\title{
Lutein Leads to a Decrease of Factor D Secretion by Cultured Mature Human Adipocytes
}

\author{
Yuan Tian, ${ }^{1}$ Aize Kijlstra, ${ }^{1}$ Johan Renes, ${ }^{2}$ Martin Wabitsch, \\ Carroll A. B. Webers, ${ }^{1}$ and Tos T. J. M. Berendschot ${ }^{1}$ \\ ${ }^{1}$ University Eye Clinic Maastricht, Postbus 5800, 6202 AZ Maastricht, Netherlands \\ ${ }^{2}$ Department of Human Biology, NUTRIM School for Nutrition, Toxicology and Metabolism, Maastricht University, \\ Maastricht, Netherlands \\ ${ }^{3}$ Sektion Pädiatrische Endokrinologie u. Diabetologie, Universität Ulm, Germany
}

Correspondence should be addressed to Tos T. J. M. Berendschot; t.berendschot@maastrichtuniversity.nl

Received 31 May 2015; Revised 20 August 2015; Accepted 27 August 2015

Academic Editor: Shun-Fa Yang

Copyright (C) 2015 Yuan Tian et al. This is an open access article distributed under the Creative Commons Attribution License, which permits unrestricted use, distribution, and reproduction in any medium, provided the original work is properly cited.

\begin{abstract}
Purpose. Complement plays an important role in the pathogenesis of age related macular degeneration (AMD) and trials are currently being conducted to investigate the effect of complement inhibition on AMD progression. We previously found that the plasma level of factor $\mathrm{D}(\mathrm{FD})$, which is the rate limiting enzyme of the complement alternative pathway, was significantly decreased following lutein supplementation. FD is synthesized by adipose tissue, which is also the main storage site of lutein. In view of these findings we tested the hypothesis whether lutein could affect FD synthesis by adipocytes. Methods. A cell line of mature human adipocytes was incubated with $50 \mu \mathrm{g} / \mathrm{mL}$ lutein for 24 and $48 \mathrm{~h}$, whereafter FD mRNA and protein expression were measured. Results. Lutein significantly inhibited adipocyte FD mRNA expression and FD protein release into adipocyte culture supernatants. Conclusions. Our earlier observations showing that a daily lutein supplement in individuals with early signs of AMD lowered the level of circulating FD might be caused by blocking adipocyte FD production.
\end{abstract}

\section{Introduction}

Age related macular degeneration (AMD) is the leading cause of irreversible visual impairment among older adults in industrialized countries and is now recognized as the third cause of global blindness [1-3]. It is a multifactorial disease with age as the most important risk factor [4]. Modifiable factors like smoking and nutrition also play a role in the development of AMD [5-9]. Of the nutrient factors, the carotenoids lutein and zeaxanthin have been shown to be beneficial in the maintenance of proper vision [10-14]. Patients with AMD often exhibit lower dietary intake of lutein compared to control subjects [15-17]. Further, intervention studies have proven that intake of antioxidant supplements containing lutein can affect the progression to the advanced stages of AMD [10-13].

Lutein and zeaxanthin are the main constituents of the macular pigment $[18,19]$. They absorb light between 390 and
$540 \mathrm{~nm}$ [20-22], thereby shielding the retina from harmful blue light that causes photochemical light damage [23]. In addition, macular pigment is capable of scavenging free radicals [24] which also results in a protective antioxidant effect in the retina [18]. Recently it has been shown that lutein also has anti-inflammatory properties [25], having beneficial effects in various models of experimental ocular inflammation, such as endotoxin induced uveitis [26], retinal ischemia $[27,28]$, and diabetic retinopathy [29-31]. This may also have implications in AMD, due to an inflammatory mechanism involving the alternative complement pathway that has recently been implicated to play a major role in the pathogenesis of AMD [32].

Various complement proteins have been found to be associated with drusen [33]. These accumulations of extracellular material are located between Bruch's membrane and the retinal pigment epithelium of the eye and their presence is a common early sign of AMD. Genetic studies furthermore 
revealed that variants in the genes of complement factors, especially complement factor $\mathrm{H}(\mathrm{CFH})$, increased the susceptibility to AMD [34-36]. In addition, various complement activation products were increased in the circulation of AMD patients, providing evidence for a systemic inflammatory component to the disease pathogenesis [37-39].

Whether lutein administration could affect the inflammatory component of AMD is not clear yet. The first clues came from studies showing that administering lutein had a beneficial effect in an experimental model of AMD [40, 41]. Recently, we have reported that daily supplementation with lutein over a time period of twelve months led to a significant decrease in the plasma levels of the complement factors: factor D (FD), C3d, C5a, and sC5b-9 [42, 43].

The activation of the alternative complement pathway involves a number of cleavage reactions and amplification steps whereby complement components interact with each other in a strictly regulated manner. FD is a rate limiting enzyme in the activation sequence of the alternative pathway and as such a key player in complement homeostasis [44, 45]. FD is also known as adipsin, since its main source is adipose tissues, where it is secreted by mature adipocytes [46]. Adipose tissue is also a main storage site for carotenoids such as lutein and zeaxanthin [47-49]. Whether lutein influences FD secretion by adipose cells is unknown and was the subject of the study described here.

\section{Methods}

2.1. Cell Culture. Simpson-Golabi-Behmel syndrome (SGBS) preadipocytes were obtained from Professor Wabitsch (University of Ulm, Ulm, Germany) [50]. These cells originate from an adipose tissue specimen of an SGBS patient and have been used for a number of studies on adipose differentiation, adipocyte glucose uptake, lipolysis, apoptosis, regulation of expression of adipokines, and protein translocation [51]. SGBS preadipocytes at generation 20 were seeded in $25 \mathrm{~cm}^{2}$ culture flasks in DMEM/F12 (Catalog number 31330, Invitrogen) containing $1 \%$ penicillin/streptomycin (P/S, Invitrogen, Catalog number 15140-122), 3.3 mM biotin (SigmaAldrich, Catalog number B-4639), $1.7 \mathrm{mM} \mathrm{D-pantothenic}$ acid (Sigma-Aldrich, Catalog number P-5155), and 10\% fetal calf serum (FCS) (Gibco Invitrogen, Breda, The Netherlands) and cultured for 6 days to reach $90 \%$ confluence. Cells were washed 3 times with phosphate buffered saline (PBS) and then changed to a serum- and albumin-free differentiation medium consisting of DMEM/F12 supplemented with $2 \mu \mathrm{mol} / \mathrm{L}$ rosiglitazone (Cayman, Catalog number 71740), $25 \mathrm{nmol} / \mathrm{L}$ dexamethasone (Sigma-Aldrich, Catalog number D-1756), 0.5 mM methyl iso-buthylxantine (Sigma-Aldrich, Catalog number I-5879), $0.1 \mu \mathrm{M}$ cortisol (Sigma-Aldrich, Catalog number H-0888), $0.01 \mathrm{mg} / \mathrm{mL}$ human transferrin (Sigma-Aldrich, Catalog number T-2252), $0.2 \mathrm{nM}$ triiodothyronine (T3, Sigma-Aldrich, Catalog number T-6397), and $20 \mathrm{nM}$ human insulin (Sigma-Aldrich, Catalog number I1507) at day 0. Medium was refreshed after two days and at day 4 the medium was changed and cells were further cultured in DMEM/F12 supplemented with $0.1 \mu \mathrm{M}$ cortisol (Sigma-Aldrich, Catalog number H-0888), $0.01 \mathrm{mg} / \mathrm{mL}$ human transferrin (Sigma-Aldrich, Catalog number T-2252), $0.2 \mathrm{nM}$ triiodothyronine (T3, Sigma-Aldrich, Catalog number T-6397), and $20 \mathrm{nM}$ human insulin (Sigma-Aldrich, Catalog number I-1507). Cells were incubated in this medium for several days and the culture medium was refreshed every two days. Small lipid droplets became visible after approximately 7 days. After 10 days, approximately $10 \%$ are differentiated and showed massive triglyceride accumulation. On culture day 20, the cells were filled with high amounts of intracellular lipids and the differentiation grade was approximately 50$60 \%$. During the whole process, all cells were cultured under humidified atmosphere containing $5 \% \mathrm{CO}_{2}$ at $37^{\circ} \mathrm{C}$.

2.2. Experimental Protocol. To study the effect of lutein (Sigma, Switzerland, Catalog number X6250, purity > 99\%), the mature adipocytes (for culture detail, see above) were washed three times with phosphate buffered saline (PBS) and then further incubated in serum-free DMEM/F12 medium for one day before treatment. The medium was supplemented with only transferrin, D-pantothenic acid, and biotin. Lutein was dissolved in dimethyl sulfoxide (DMSO, Sigma, Switzerland, Catalog number D8418, BioReagent, for molecular biology, purity $\geq 99.9 \%$ ) and then serially diluted to the working concentrations with DMEM/F12 culture medium. As vehicle control we used the same medium with $0.5 \%$ DMSO solvent. The lutein concentration of $50 \mu \mathrm{g} / \mathrm{mL}(\mathrm{v} / \mathrm{v})$ was chosen after performing pilot experiments comparing different concentrations $(0.5 \mu \mathrm{g} / \mathrm{mL}-50 \mu \mathrm{g} / \mathrm{mL}$, data not shown).

2.3. Enzyme-Linked Immunosorbent Assay. Supernatants from mature adipocytes cultured with or without lutein were collected after 24 and 48 hours and stored at $-80^{\circ} \mathrm{C}$ for FD measurements. The secretion level of FD was measured at a 1/100 dilution by using a commercially available development kit (DuoSet) for human complement factor D (R\&D Systems, Minneapolis, USA) according to the manufacturer's instructions.

2.4. Quantitative Real-Time PCR ( $q R T-P C R)$. The expression of FD mRNA was assessed by quantitative real-time PCR (qRT-PCR). Total RNA was isolated from the mature adipocytes incubated with or without lutein for 48 hours by using the RNeasy Mini Kit (Qiagen Westburg, Leusden, The Netherlands) according to the manufacturer's protocol. The quantity and purity of the mRNA were measured by using the NanoDrop system (Thermo Scientific, USA). $500 \mathrm{ng}$ of each RNA sample was reverse transcribed for the first-strand cDNA by using the iScript cDNA synthesis kit protocol (BioRad Laboratories B.V., The Netherlands) and then diluted 40 times with distilled water. The following primers were purchased from Operon (Sigma-Aldrich, The Netherlands) and used for real-time PCR (FD forward $5^{\prime}$-GTCCTGGTGGCGGAGC-3', reverse $5^{\prime}$-AGAACCTGCACCTTCCCGTC- $3^{\prime}: \beta$-actin forward $5^{\prime}$-GACTACCTCATGAAGATCCT- $3^{\prime}$, reverse $5^{\prime}$-GCGGATGTCCACGTCACACT- $3^{\prime}$ ). The mixture reaction contained $12.5 \mu \mathrm{L}$ SYBR $^{\odot}$ Green Supermix (Bio-Rad), $5 \mu \mathrm{L}$ diluted $\mathrm{cDNA}$, and $0.3 \mu \mathrm{M}$ primers in 


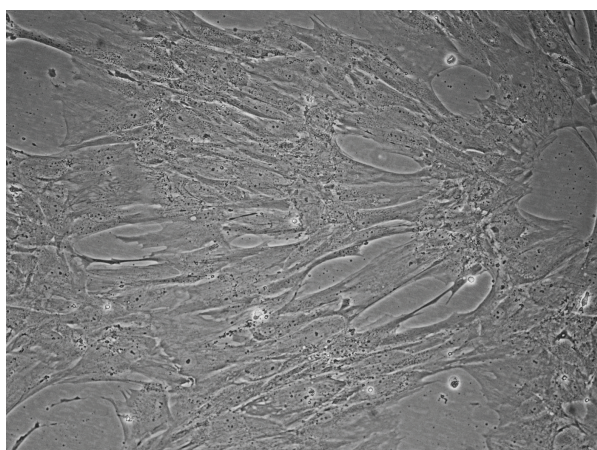

Day 0

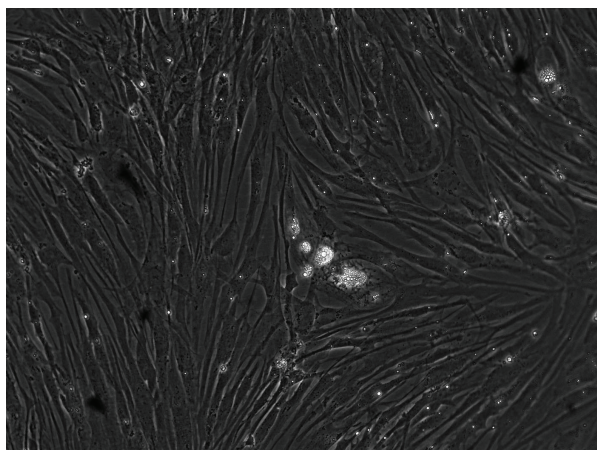

Day 14

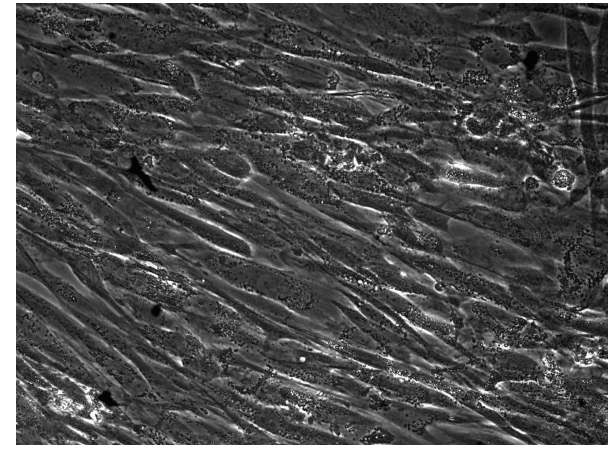

Day 7

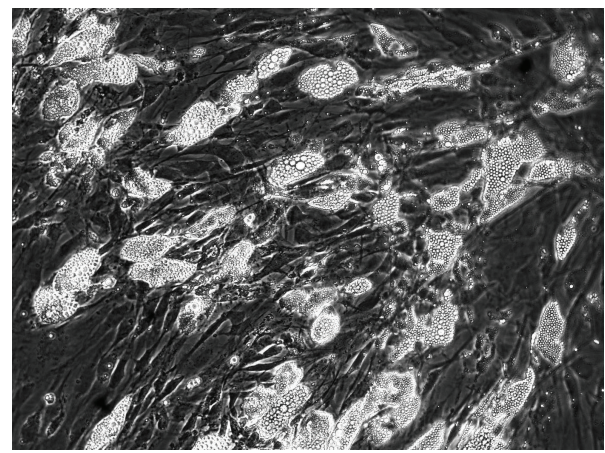

Day 20

FIGURE 1: The differentiation process of SGBS preadipocytes to mature adipocytes at days $0,7,14$, and 20.

a total volume of $25 \mu \mathrm{L}$. The two-step qRT-PCR was performed under the following cycling conditions which consisted of an initial denaturation at $95^{\circ} \mathrm{C}$ for $3 \mathrm{~min}$, followed by 40 alternating cycles of $95^{\circ} \mathrm{C}$ for $10 \mathrm{sec}$ and $55^{\circ} \mathrm{C}$ for $45 \mathrm{sec}$, respectively. All PCR reactions included a cDNA dilution curve to assess PCR efficiency and all reactions were followed by a melt curve $\left(55-95^{\circ} \mathrm{C}\right)$. Data were analyzed by using MyiQ Software system (Bio-Rad) and the amount of target cDNA in each sample was determined by a fractional PCR threshold cycle number (Ct-value) and compared to the corresponding $\mathrm{Ct}$-value for the housekeeping gene $\beta$-actin. The relative gene expression level for each gene was calculated by using the 2Delta Delta C(T) method [52].

2.5. Statistical Analysis. Statistical analysis was performed using SPSS 20.0.0; one-way analysis of variance (ANOVA) with Post hoc Bonferroni test was used for data analysis. All values are expressed as mean \pm standard error of the mean (SEM). A value of $p<0.05$ was considered statistically significant.

\section{Results}

3.1. The Differentiation Process of SGBS Adipocytes. SGBS preadipocytes were differentiated into mature adipocytes during 20 days. Lipid accumulation became visible after 7 days and increased further during the differentiation period (Figure 1). After 20 days, approximately $50-60 \%$ of the cells were fully differentiated as demonstrated by the massive triglyceride accumulation.
3.2. The Effect of Lutein on FD Secretion by Mature Adipocytes. Lutein was added to mature adipocyte cultures and the mean FD concentration in the culture medium was measured at $24 \mathrm{~h}$ and $48 \mathrm{~h}$. As control, adipocyte cultures that contain the similar medium with DMSO only (vehicle control) or cells with medium only (blank group) were used (Figure 2). The mean FD concentration increased with time in the blank group from $155.3 \pm 3.1 \mathrm{ng} / \mathrm{mL}$ at $24 \mathrm{~h}$ to $311.8 \pm$ $10.2 \mathrm{ng} / \mathrm{mL}$ at $48 \mathrm{~h}$. In the DMSO vehicle control group the mean FD concentration increased from $174.1 \pm 4.3 \mathrm{ng} / \mathrm{mL}$ to $357.6 \pm 14.5 \mathrm{ng} / \mathrm{mL}$ between the $24 \mathrm{~h}$ and $48 \mathrm{~h}$ time points, respectively. Addition of lutein to the cultures resulted in a decreased concentration of FD as compared to the two control groups. Particularly, a significantly decreased FD level was observed when comparing the lutein group with the vehicle control group: $174.1 \pm 4.3 \mathrm{ng} / \mathrm{mL}$ (DMSO control) versus $133.3 \pm 11.9 \mathrm{ng} / \mathrm{mL}$ (lutein) $(p<0.0001)$ at $24 \mathrm{~h}$ and $357.6 \pm 14.5 \mathrm{ng} / \mathrm{mL}$ (DMSO control) versus $271.1 \pm$ $38.7 \mathrm{ng} / \mathrm{mL}$ (lutein) $(p=0.002)$ at $48 \mathrm{~h}$. When comparing the blank control with the DMSO vehicle control, it is clear that DMSO resulted in a slight increase in the FD production by the adipocytes: $155.3 \pm 3.1 \mathrm{ng} / \mathrm{mL}$ (blank control) versus $174.1 \pm 4.3 \mathrm{ng} / \mathrm{mL}$ (DMSO control) at $24 \mathrm{~h}(p=0.017)$ and $311.8 \pm 10.2 \mathrm{ng} / \mathrm{mL}$ (blank control) versus $357.6 \pm 14.5 \mathrm{ng} / \mathrm{mL}$ (DMSO control) at $48 \mathrm{~h}(p=0.081)$.

3.3. Lutein Downregulated the $m R N A$ Expression of FD in Adipocytes. The aforementioned results showed that lutein inhibited FD protein secretion. To examine whether lutein also affects FD mRNA expression in adipocytes we harvested 


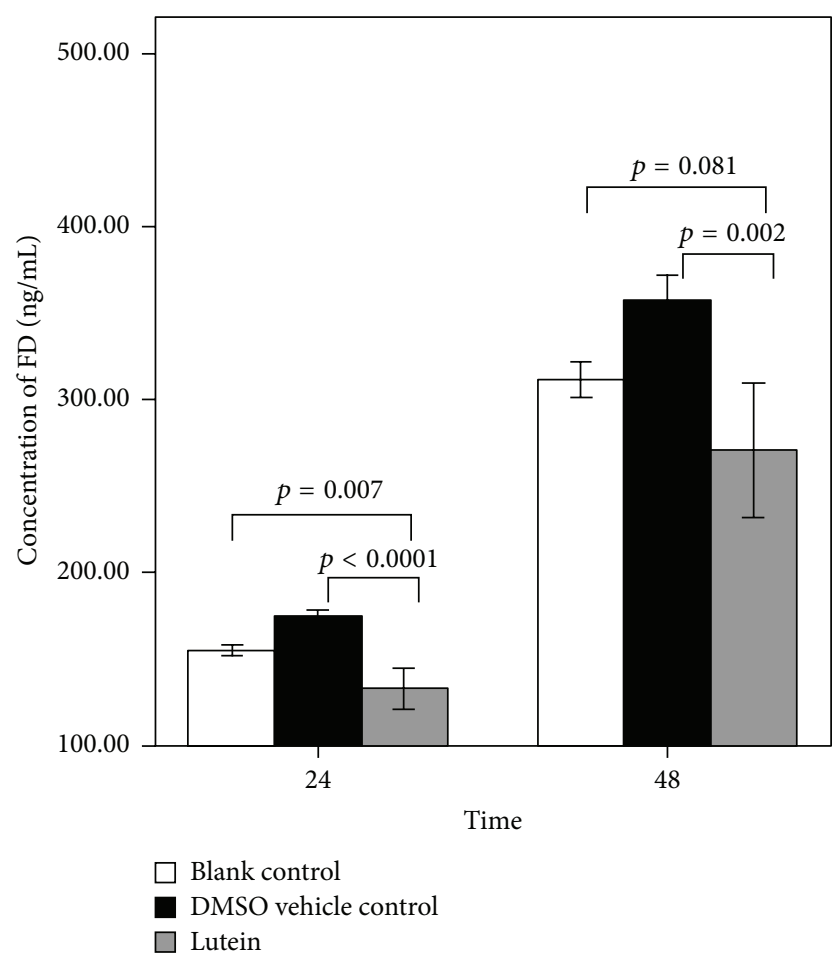

FIGURE 2: Factor D (FD) concentration in culture medium from 20-day differentiated SGBS adipocytes incubated for $24 \mathrm{~h}$ and $48 \mathrm{~h}$ in culture medium (blank control), 0.5\% DMSO (DMSO vehicle control), or lutein $(50 \mu \mathrm{g} / \mathrm{mL})$ in the presence of $0.5 \%$ DMSO (lutein).

20-day differentiated SGBS adipocytes that were incubated for an additional $48 \mathrm{~h}$ with lutein. We performed a qPCR analysis whereby FD mRNA expression was measured relative to $\beta$-actin mRNA (household gene). The results showed that incubation of mature SGBS adipocytes with lutein for 48 hours significantly downregulated FD mRNA expression when compared to both the blank control and the vehicle control (DMSO) $(p<0.0001$ and $p<0.0001$, resp.) (Figure 3). No difference was observed in the mRNA expression between the DMSO group and the blank group ( $p=$ 0.37).

\section{Discussion}

In this study we show that lutein suppresses factor D (FD) expression in mature SGBS adipocytes, both at the level of protein secretion and at the mRNA level. To the best of our knowledge, this is the first study to examine the influence of lutein on the expression of FD in human adipocytes. Adding lutein to SGBS adipocyte cultures resulted in a $23 \%$ reduction at 24 hours and a $24 \%$ reduction at 48 hours of the release of FD as compared to vehicle controls. Adipose tissue is the main source of FD [46] and earlier data using SGBS adipocytes already showed that these cells were able to secrete FD [53]. At the same time, adipose tissue also serves as the main storage site for carotenoids such as lutein and these facts prompted us to study a possible interaction between these two factors [54]. The in vitro observations from this study

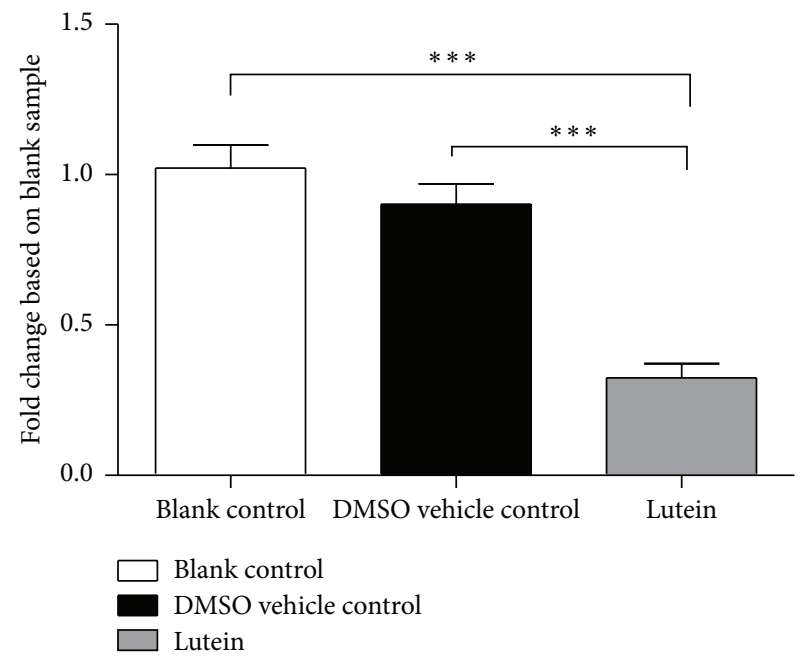

FIGURE 3: Factor D mRNA expression in 20-day differentiated SGBS adipocytes incubated for $48 \mathrm{~h}$ with culture medium (blank control), $0.5 \%$ DMSO (DMSO vehicle control), or lutein $(50 \mu \mathrm{g} / \mathrm{mL})$ in the presence of $0.5 \%$ DMSO (lutein). Bars represent fold change of FD mRNA expression compared to blank control $\left({ }^{* * *} p<0.0001\right)$.

support our earlier in vivo findings showing that taking a lutein supplement reduces circulating FD levels [42].

How lutein is taken up by adipocytes is not clear yet. Lutein biosynthesis only occurs in plants, algae, bacteria, and certain fungi. Humans cannot make lutein and uptake is dependent on the dietary intake of certain fruits, leafy vegetables, or eggs [55]. In the gut, lutein is taken up by enterocytes, packed into chylomicrons, and then transported via lymphatics, thoracic duct, and bloodstream to the liver hepatocytes [56]. In the hepatocytes it is bound to lipoproteins and then transported via the blood to various sites in the body including the retina and adipose tissue [57]. Body fat is an important storage site for lutein and it may compete with other tissues, thereby making it less available for the macula [58]. Possible differences in adipose tissue composition and distribution may explain differences observed in lutein metabolism between men and women [59]. Both lutein and factor $\mathrm{D}$ have separately been implicated in the pathogenesis of AMD and our observation linking these two factors is a novel observation [60].

The presence of FD in adipose tissue has been attributed to its role in the local cleavage of complement component $\mathrm{C} 3$, thereby forming C3a [61]. The carboxy-terminal arginine of $\mathrm{C} 3 \mathrm{a}$ is subsequently cleaved by carboxypeptidase $\mathrm{N}$ to generate C3a-desarg, also known as acylation stimulating protein (ASP) [62]. ASP interacts with the ASP receptor (C5L2) on adipocytes, thereby triggering triglyceride synthesis [62].

How FD expression is regulated in adipose tissue did not receive much attention yet. FD mRNA expression is increased during the differentiation of preadipocytes to adipocytes [63]. In addition, FD secretion was measured in the medium of SGBS adipocytes but not in the medium of SGBS preadipocytes [53]. On the other hand, in vitro stimulation with retinoic acid (RA) resulted in a 4-5-fold 
suppression of FD mRNA expression by mouse adipocytes [64].

Under normal conditions an adipocyte will already have a lutein store inside the cells [59]. The amount of lutein in adipose tissue ranges between $0.09 \mathrm{Mol}(\mathrm{men})$ and $0.36 \mathrm{Mol}$ (women) [59], which is a few thousandfold higher than the dose $(50 \mu \mathrm{g} / \mathrm{mL}$ is equivalent to $87 \mu \mathrm{Mol})$ used in our study to load the cells. The SGBS cells we used were cultured under lutein-free conditions and will thus not yet have acquired lutein inside the cells. In our experiments we cultured the SGBS cells for up to 48 hours with lutein with a dose that is much higher than that found in human plasma $(0.22 \mu \mathrm{Mol})$ [25]. Using this short time period we found that lower doses than the $50 \mu \mathrm{g} / \mathrm{mL}$ did not have an effect. Further experiments should be done using both longer and shorter time intervals and with varying doses of lutein to investigate how different adipose lutein levels might affect FD expression in our in vitro model. As mentioned above, an adipocyte in the human body already contains a certain concentration of lutein and we believe that the level of lutein in an adipocyte will control the steady-state production of FD. Future experiments with adipose tissue taken from humans whereby lutein content is correlated with FD levels will provide evidence to show whether this hypothesis is correct.

The blood level of ASP (C3a-desarg) has been shown to be increased in patients with AMD and this has added support to the hypothesis that AMD is a disease caused by a hyperactive alternative complement pathway [65]. FD levels have also been found to be increased in the blood of AMD patients [36, 37]. As mentioned earlier, FD is the rate limiting enzyme of the alternative pathway and small changes in its concentration can potentially have profound effects on the generation of biologically active products such as C3a, C3adesarg, and C5a.

Obesity has been shown to be a risk factor for AMD but the exact role of adipose tissue in the pathogenesis of AMD is not yet clear $[7,66]$. Plasma levels of FD are associated with body mass index (BMI) and were shown to be higher in obese versus nonobese subjects [67]. The evidence shown above suggests a possible role for adipocyte biology in AMD pathogenesis [60].

A role for FD in retinal disease became apparent from an experimental mouse model showing that photoreceptors were protected from light induced damage in FD knockout animals [68]. Control of FD has now been brought to the clinic with the availability of a humanized IgG Fab murine anti-factor D antibody (FCFD4514S) that has been shown to block the formation of the alternative pathway C3 convertase [69]. The FD antibody was named Lampalizumab, and phase 1 and phase 2 trials, whereby it was given intravitreally in patients with geographic atrophy, have shown promising results [70] and are now followed by two phase- 3 trials (these trials are registered with https://clinicaltrials.gov/).

In conclusion, we have shown that lutein suppresses FD expression in and secretion by human SGBS adipocytes. This observation may explain the decrease in circulating FD with daily lutein supplementation that we observed in an earlier study [42]. It might offer a novel therapeutic approach to prevent the progression of AMD and other inflammatory diseases that are modulated by FD.

\section{Conflict of Interests}

The authors declare that there is no conflict of interests regarding the publication of this paper.

\section{Acknowledgments}

This work was supported by a personal grant (Yuan Tian) from the Chinese Scholarship Council (CSC). The study was further supported by the following foundations: $\mathrm{MD}$ Fonds, Novartis, ANVVB, and LSBS that contributed through UitZicht. The funding organizations had no role in the design or conduct of this research. They provided unrestricted grants.

\section{References}

[1] R. Klein, T. Peto, A. Bird, and M. R. Vannewkirk, "The epidemiology of age-related macular degeneration," American Journal of Ophthalmology, vol. 137, no. 3, pp. 486-495, 2004.

[2] D. S. Friedman, B. J. O’Colmain, B. Muñoz et al., "Prevalence of age-related macular degeneration in the United States," Archives of Ophthalmology, vol. 122, no. 4, pp. 564-572, 2004.

[3] M. A. Bamashmus, B. Matlhaga, and G. N. Dutton, "Causes of blindness and visual impairment in the West of Scotland," Eye, vol. 18, no. 3, pp. 257-261, 2004.

[4] R. D. Jager, W. F. Mieler, and J. W. Miller, "Age-related macular degeneration," The New England Journal of Medicine, vol. 358, no. 24, pp. 2544-2617, 2008.

[5] L. S. Lim, P. Mitchell, J. M. Seddon, F. G. Holz, and T. Y. Wong, "Age-related macular degeneration," The Lancet, vol. 379, no. 9827, pp. 1728-1738, 2012.

[6] W. Smith, J. Assink, R. Klein et al., "Risk factors for age-related macular degeneration: pooled findings from three continents," Ophthalmology, vol. 108, no. 4, pp. 697-704, 2001.

[7] J. M. Seddon, J. Cote, N. Davis, and B. Rosner, "Progression of age-related macular degeneration: association with body mass index, waist circumference, and waist-hip ratio," Archives of Ophthalmology, vol. 121, no. 6, pp. 785-792, 2003.

[8] J. M. Seddon, J. Cote, and B. Rosner, "Progression of age-related macular degeneration: association with dietary fat, transunsaturated fat, nuts, and fish intake," Archives of Ophthalmology, vol. 121, no. 12, pp. 1728-1737, 2003.

[9] C. E. Myers, B. E. Klein, R. Gangnon, T. A. Sivakumaran, S. K. Iyengar, and R. Klein, "Cigarette smoking and the natural history of age-related macular degeneration: the beaver dam eye study," Ophthalmology, vol. 121, no. 10, pp. 1949-1955, 2014.

[10] M. Mozaffarieh, S. Sacu, and A. Wedrich, "The role of the carotenoids, lutein and zeaxanthin, in protecting against agerelated macular degeneration: a review based on controversial evidence," Nutrition Journal, vol. 2, article 20, 2003.

[11] C. Delcourt, I. Carrière, M. Delage et al., "Plasma lutein and zeaxanthin and other carotenoids as modifiable risk factors for age-related maculopathy and cataract: the POLA study," Investigative Ophthalmology \& Visual Science, vol. 47, no. 6, pp. 2329-2335, 2006. 
[12] E. Y. Chew, J. P. SanGiovanni, F. L. Ferris et al., "Lutein/zeaxanthin for the treatment of age-related cataract: AREDS2 randomized trial report no. 4," JAMA Ophthalmology, vol. 131, no. 7, pp. 843-850, 2013.

[13] M. E. Aronow and E. Y. Chew, "Age-related Eye Disease Study 2: perspectives, recommendations, and unanswered questions," Current Opinion in Ophthalmology, vol. 25, no. 3, pp. 186-190, 2014.

[14] J. A. Mares-Perlman, A. I. Fisher, R. Klein et al., "Lutein and zeaxanthin in the diet and serum and their relation to agerelated maculopathy in the third national health and nutrition examination survey," American Journal of Epidemiology, vol. 153, no. 5, pp. 424-432, 2001.

[15] R. van Leeuwen, S. Boekhoorn, J. R. Vingerling et al., "Dietary intake of antioxidants and risk of age-related macular degeneration," Journal of the American Medical Association, vol. 294, no. 24, pp. 3101-3107, 2005.

[16] K. Hesterberg, S. Schanzer, A. Patzelt et al., "Raman spectroscopic analysis of the carotenoid concentration in egg yolks depending on the feeding and housing conditions of the laying hens," Journal of Biophotonics, vol. 5, no. 1, pp. 33-39, 2012.

[17] J. M. Seddon, U. A. Ajani, R. D. Sperduto et al., "Dietary carotenoids, vitamins $\mathrm{A}, \mathrm{C}$, and $\mathrm{E}$, and advanced age-related macular degeneration. Eye disease case-control study group," The Journal of the American Medical Association, vol. 272, no. 18, pp. 1413-1420, 1994.

[18] N. P. Davies and A. B. Morland, "Macular pigments: their characteristics and putative role," Progress in Retinal and Eye Research, vol. 23, no. 5, pp. 533-559, 2004.

[19] R. A. Bone, J. T. Landrum, L. Fernandez, and S. L. Tarsis, "Analysis of the macular pigment by HPLC: retinal distribution and age study," Investigative Ophthalmology and Visual Science, vol. 29, no. 6, pp. 843-849, 1988.

[20] P. DeMarco, J. Pokorny, and V. C. Smith, "Full-spectrum cone sensitivity functions for X-chromosome-linked anomalous trichromats," Journal of the Optical Society of America A, vol. 9, no. 9, pp. 1465-1476, 1992.

[21] R. A. Bone, J. T. Landrum, and A. Cains, "Optical density spectra of the macular pigment in vivo and in vitro," Vision Research, vol. 32, no. 1, pp. 105-110, 1992.

[22] L. T. Sharpe, A. Stockman, H. Knau, and H. Jägle, "Macular pigment densities derived from central and peripheral spectral sensitivity differences," Vision Research, vol. 38, no. 21, pp. 32333239, 1998.

[23] J. T. Landrum, R. A. Bone, and M. D. Kilburn, "The macular pigment: a possible role in protection from age-related macular degeneration," Advances in Pharmacology, vol. 38, pp. 537-556, 1997.

[24] F. Khachik, P. S. Bernstein, and D. L. Garland, "Identification of lutein and zeaxanthin oxidation products in human and monkey retinas," Investigative Ophthalmology and Visual Science, vol. 38, no. 9, pp. 1802-1811, 1997.

[25] A. Kijlstra, Y. Tian, E. R. Kelly, and T. T. J. M. Berendschot, "Lutein: more than just a filter for blue light," Progress in Retinal and Eye Research, vol. 31, no. 4, pp. 303-315, 2012.

[26] X.-H. Jin, K. Ohgami, K. Shiratori et al., "Inhibitory effects of lutein on endotoxin-induced uveitis in Lewis rats," Investigative Ophthalmology and Visual Science, vol. 47, no. 6, pp. 2562-2568, 2006.

[27] S.-Y. Li, Z.-J. Fu, H. Ma et al., "Effect of lutein on retinal neurons and oxidative stress in a model of acute retinal ischemia/reperfusion," Investigative Ophthalmology and Visual Science, vol. 50, no. 2, pp. 836-843, 2009.

[28] S.-Y. Li and A. C. Y. Lo, "Lutein protects RGC-5 cells against hypoxia and oxidative stress," International Journal of Molecular Sciences, vol. 11, no. 5, pp. 2109-2117, 2010.

[29] M. Muriach, F. Bosch-Morell, G. Alexander et al., "Lutein effect on retina and hippocampus of diabetic mice," Free Radical Biology and Medicine, vol. 41, no. 6, pp. 979-984, 2006.

[30] M. Sasaki, Y. Ozawa, T. Kurihara et al., "Neurodegenerative influence of oxidative stress in the retina of a murine model of diabetes," Diabetologia, vol. 53, no. 5, pp. 971-979, 2010.

[31] L. Brazionis, K. Rowley, C. Itsiopoulos, and K. O’Dea, "Plasma carotenoids and diabetic retinopathy, British Journal of Nutrition, vol. 101, no. 2, pp. 270-277, 2009.

[32] S. Khandhadia, V. Cipriani, J. R. W. Yates, and A. J. Lotery, "Agerelated macular degeneration and the complement system," Immunobiology, vol. 217, no. 2, pp. 127-146, 2012.

[33] M. Nozaki, B. J. Raisler, E. Sakurai et al., "Drusen complement components C3a and C5a promote choroidal neovascularization," Proceedings of the National Academy of Sciences of the United States of America, vol. 103, no. 7, pp. 2328-2333, 2006.

[34] A. O. Edwards, R. Ritter III, K. J. Abel, A. Manning, C. Panhuysen, and L. A. Farrer, "Complement factor H polymorphism and age-related macular degeneration," Science, vol. 308, no. 5720, pp. 421-424, 2005.

[35] R. J. Klein, C. Zeiss, E. Y. Chew et al., "Complement factor H polymorphism in age-related macular degeneration," Science, vol. 308, no. 5720, pp. 385-389, 2005.

[36] L. A. Hecker, A. O. Edwards, E. Ryu et al., "Genetic control of the alternative pathway of complement in humans and age-related macular degeneration," Human Molecular Genetics, vol. 19, no. 1, pp. 209-215, 2010.

[37] H. P. N. Scholl, P. C. Issa, M. Walier et al., "Systemic complement activation in age-related macular degeneration," PLOS ONE, vol. 3, no. 7, Article ID e2593, 2008.

[38] R. Reynolds, M. E. Hartnett, J. P. Atkinson, P. C. Giclas, B. Rosner, and J. M. Seddon, "Plasma complement components and activation fragments: associations with age-related macular degeneration genotypes and phenotypes," Investigative Ophthalmology and Visual Science, vol. 50, no. 12, pp. 5818-5827, 2009.

[39] A. S. Silva, A. G. Teixeira, L. Bavia et al., "Plasma levels of complement proteins from the alternative pathway in patients with age-related macular degeneration are independent of complement factor $\mathrm{H}$ Tyr ${ }^{402}$ His polymorphism," Molecular Vision, vol. 18, pp. 2288-2299, 2012.

[40] A. Kijlstra, E. C. La Heij, and F. Hendrikse, "Immunological factors in the pathogenesis and treatment of age-related macular degeneration," Ocular Immunology and Inflammation, vol. 13, no. 1, pp. 3-11, 2005.

[41] K. Izumi-Nagai, N. Nagai, K. Ohgami et al., "Macular pigment lutein is antiinflammatory in preventing choroidal neovascularization," Arteriosclerosis, Thrombosis, and Vascular Biology, vol. 27, no. 12, pp. 2555-2562, 2007.

[42] Y. Tian, A. Kijlstra, R. L. P. van der Veen, M. Makridaki, I. J. Murray, and T. T. J. M. Berendschot, "The effect of lutein supplementation on blood plasma levels of complement factor D, C5a and C3d," PLoS ONE, vol. 8, no. 8, Article ID e73387, 2013.

[43] Y. Tian, A. Kijlstra, R. L. P. van der Veen, M. Makridaki, I. J. Murray, and T. T. J. M. Berendschot, "Lutein supplementation 
leads to decreased soluble complement membrane attack complex sC5b-9 plasma levels," Acta Ophthalmologica, vol. 93, no. 2, pp. 141-145, 2015.

[44] P. H. Lesavre and H. J. Muller-Eberhard, "Mechanism of action of factor D of the alternative complement pathway," The Journal of Experimental Medicine, vol. 148, no. 6, pp. 1498-1509, 1978.

[45] H. Jing, Y. S. Babu, D. Moore et al., "Structures of native and complexed complement factor D: Implications of the atypical His57 conformation and self-inhibitory loop in the regulation of specific serine protease activity," Journal of Molecular Biology, vol. 282, no. 5, pp. 1061-1081, 1998.

[46] R. T. White, D. Damm, N. Hancock et al., "Human adipsin is identical to complement factor D and is expressed at high levels in adipose tissue," The Journal of Biological Chemistry, vol. 267, no. 13, pp. 9210-9213, 1992.

[47] H.-Y. Chung, A. L. A. Ferreira, S. Epstein, S. A. R. Paiva, C. Castaneda-Sceppa, and E. J. Johnson, "Site-specific concentrations of carotenoids in adipose tissue: relations with dietary and serum carotenoid concentrations in healthy adults," The American Journal of Clinical Nutrition, vol. 90, no. 3, pp. 533$539,2009$.

[48] J. A. Olson, "Serum levels of vitamin A and carotenoids as reflectors of nutritional status," Journal of the National Cancer Institute, vol. 73, no. 6, pp. 1439-1444, 1984.

[49] R. S. Parker, "Carotenoids in human blood and tissues," Journal of Nutrition, vol. 119, no. 1, pp. 101-104, 1989.

[50] M. Wabitsch, R. E. Brenner, I. Melzner et al., "Characterization of a human preadipocyte cell strain with high capacity for adipose differentiation," International Journal of Obesity and Related Metabolic Disorders, vol. 25, no. 1, pp. 8-15, 2001.

[51] P. Fischer-Posovszky, F. S. Newell, M. Wabitsch, and H. E. Tornqvist, "Human SGBS cells-a unique tool for studies of human fat cell biology," Obesity Facts, vol. 1, no. 4, pp. 184-189, 2008.

[52] K. J. Livak and T. D. Schmittgen, "Analysis of relative gene expression data using real-time quantitative PCR and the $2^{-\Delta \Delta C_{\mathrm{T}}}$ method," Methods, vol. 25, no. 4, pp. 402-408, 2001.

[53] A. Rosenow, T. N. Arrey, F. G. Bouwman et al., "Identification of novel human adipocyte secreted proteins by using SGBS cells," Journal of Proteome Research, vol. 9, no. 10, pp. 5389-5401, 2010.

[54] H.-Y. Chung, H. M. Rasmussen, and E. J. Johnson, "Lutein bioavailability is higher from lutein-enriched eggs than from supplements and spinach in men," Journal of Nutrition, vol. 134, no. 8, pp. 1887-1893, 2004.

[55] M. M. Calvo, "Lutein: a valuable ingredient of fruit and vegetables," Critical Reviews in Food Science and Nutrition, vol. 45, no. 7-8, pp. 671-696, 2005.

[56] H. C. Furr and R. M. Clark, "Intestinal absorption and tissue distribution of carotenoids," Journal of Nutritional Biochemistry, vol. 8, no. 7, pp. 364-377, 1997.

[57] B. A. Clevidence and J. G. Bieri, "Association of carotenoids with human plasma lipoproteins," Methods in Enzymology, vol. 214, pp. 33-46, 1993.

[58] E. R. Bovier, R. D. Lewis, and B. R. Hammond Jr., "The relationship between lutein and zeaxanthin status and body fat," Nutrients, vol. 5, no. 3, pp. 750-757, 2013.

[59] E. J. Johnson, B. R. Hammond, K.-J. Yeum et al., "Relation among serum and tissue concentrations of lutein and zeaxanthin and macular pigment density," The American Journal of Clinical Nutrition, vol. 71, no. 6, pp. 1555-1562, 2000.
[60] Y. Tian, A. Kijlstra, C. A. B. Webers, and T. T. J. M. Berendschot, "Lutein and Factor D: two intriguing players in the field of age-related macular degeneration," Archives of Biochemistry and Biophysics, vol. 572, pp. 49-53, 2015.

[61] M. Maslowska, H. W. Wang, and K. Cianflone, "Novel roles for acylation stimulating protein/C3adesArg: a review of recent in vitro and in vivo evidence," Vitamins and Hormones, vol. 70, pp. 309-332, 2005.

[62] W. D. Campbell, E. Lazoura, N. Okada, and H. Okada, "Inactivation of C3a and C5a octapeptides by carboxypeptidase $\mathrm{R}$ and carboxypeptidase N," Microbiology and Immunology, vol. 46, no. 2, pp. 131-134, 2002.

[63] K. Cianflone and M. Maslowska, "Differentiation-induced production of ASP in human adipocytes," European Journal of Clinical Investigation, vol. 25, no. 11, pp. 817-825, 1995.

[64] J. Antras, F. Lasnier, and J. Pairault, "Adipsin gene expression in 3T3-F442A adipocytes is posttranscriptionally down-regulated by retinoic acid," The Journal of Biological Chemistry, vol. 266, no. 2, pp. 1157-1161, 1991.

[65] N. S. Bora, S. Kaliappan, P. Jha et al., "Complement activation via alternative pathway is critical in the development of laserinduced choroidal neovascularization: role of factor B and factor H," The Journal of Immunology, vol. 177, no. 3, pp. 18721878, 2006.

[66] M. G. Erke, G. Bertelsen, T. Peto, A. K. Sjølie, H. Lindekleiv, and I. Njølstad, "Cardiovascular risk factors associated with age-related macular degeneration: the Tromsø study," Acta Ophthalmologica, vol. 92, no. 7, pp. 662-669, 2014.

[67] E. Hertle, C. D. A. Stehouwer, and M. M. J. van Greevenbroek, "The complement system in human cardiometabolic disease," Molecular Immunology, vol. 61, no. 2, pp. 135-148, 2014.

[68] B. Rohrer, Y. Guo, K. Kunchithapautham, and G. S. Gilkeson, "Eliminating complement factor D reduces photoreceptor susceptibility to light-induced damage," Investigative Ophthalmology \& Visual Science, vol. 48, no. 11, pp. 5282-5289, 2007.

[69] K. J. Katschke Jr., P. Wu, R. Ganesan et al., "Inhibiting alternative pathway complement activation by targeting the factor D exosite," The Journal of Biological Chemistry, vol. 287, no. 16, pp. 12886-12892, 2012.

[70] D. V. Do, D. J. Pieramici, M. van Lookeren Campagne et al., "A phase ia dose-escalation study of the anti-factor D monoclonal antibody fragment FCFD4514S in patients with geographic atrophy," Retina, vol. 34, no. 2, pp. 313-320, 2014. 


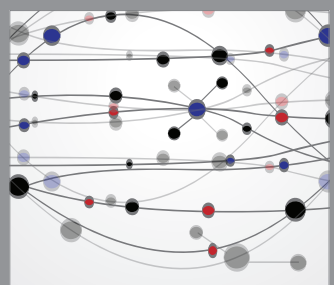

The Scientific World Journal
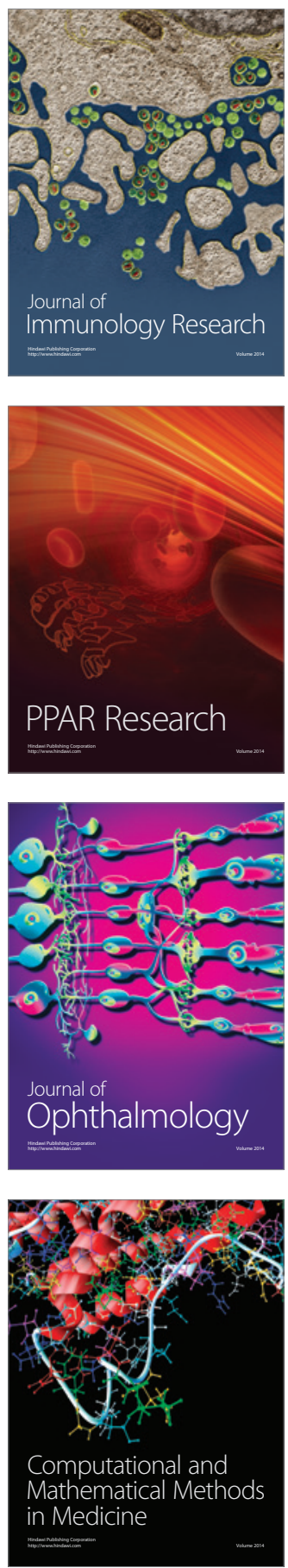

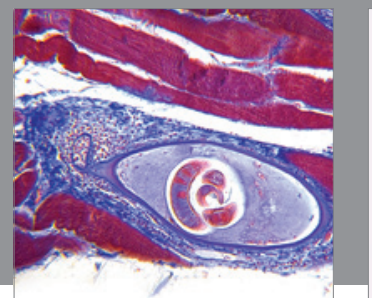

Gastroenterology

Research and Practice
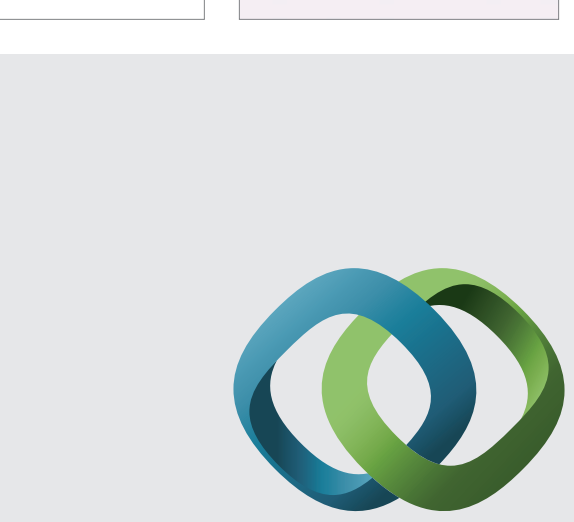

\section{Hindawi}

Submit your manuscripts at

http://www.hindawi.com
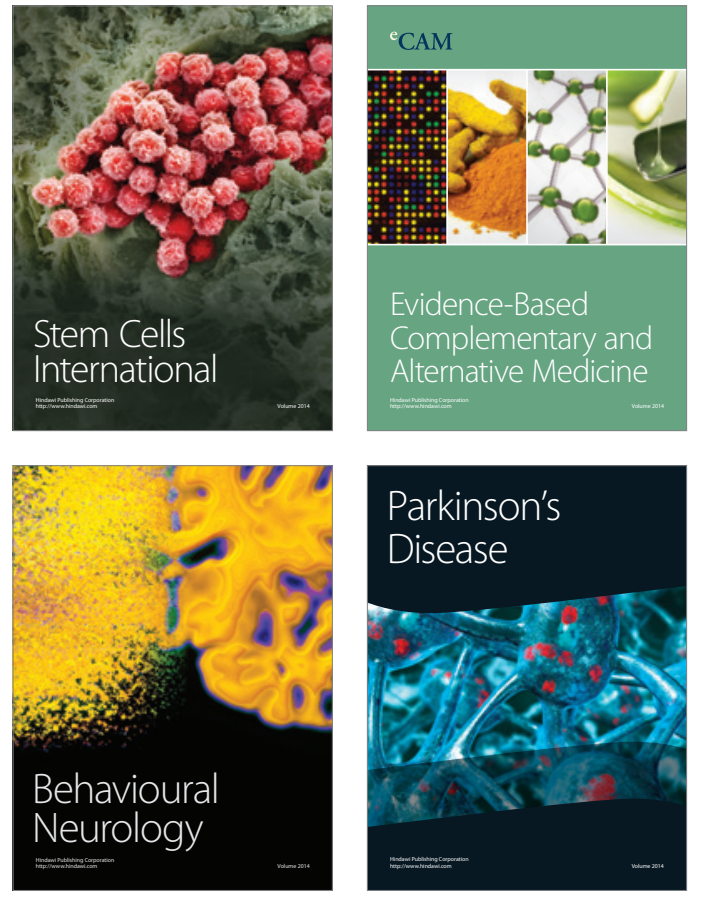
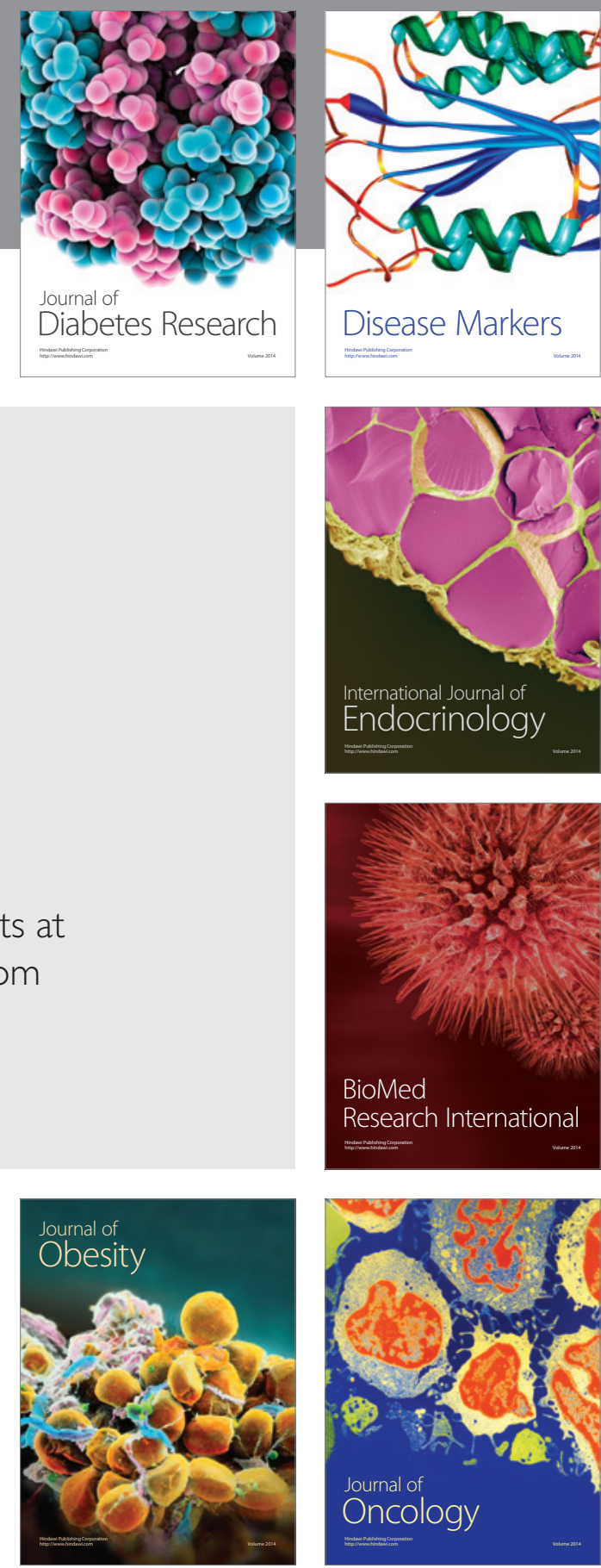

Disease Markers
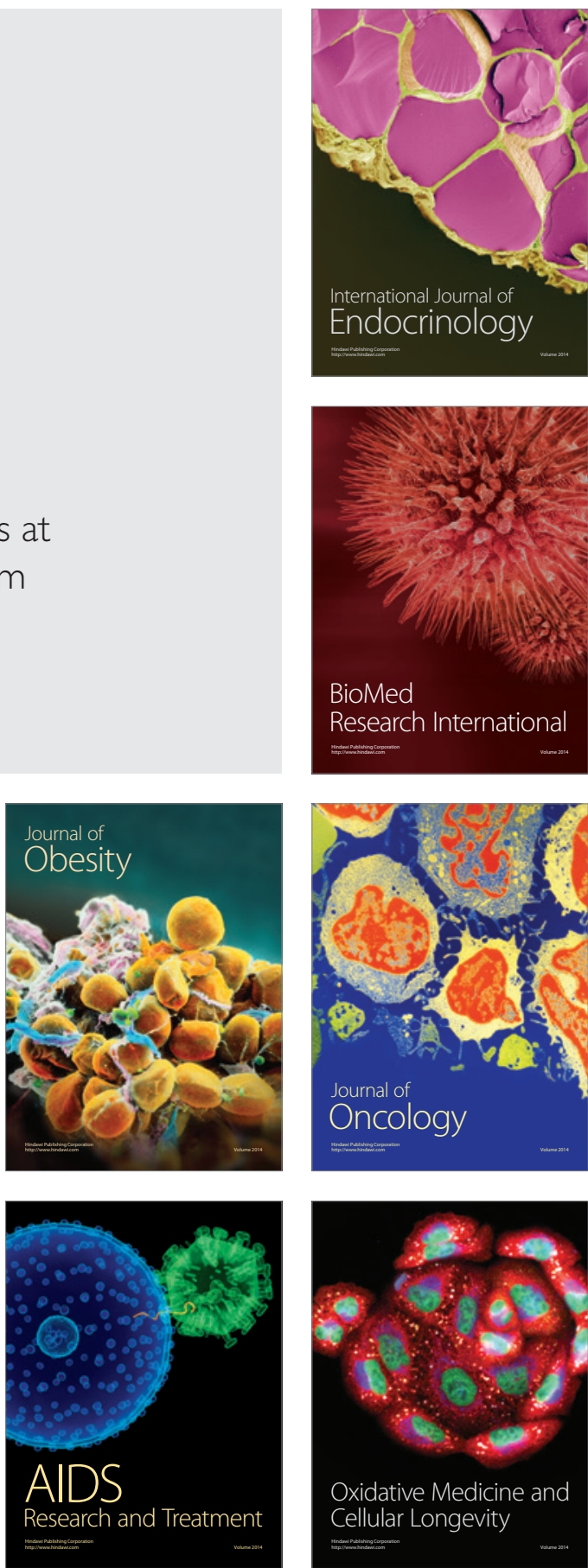